\title{
Comunicación

\section{Diversidad de exposición de jóvenes neoleoneses, guanajuatenses $y$ quintanarroenses a la televisión y al cine}

Diversity of rates of exposure to television and film of young publics in the states of Nuevo León, Guanajuato and Quintana Roo

\section{OSCAR MARIO MIRANDA VILLANUEVA ${ }^{1}$}

La investigación trata de explicar patrones de consumo de jóvenes a programas y películas vistos en sistemas de televisión y salas cinematográficas. Basados en la información de 21 entrevistas focalizadas, los hallazgos muestran una estrecha relación entre la diversidad de contenido y exposición de los jóvenes entrevistados. Trabajos futuros podrían evidenciar nuestros hallazgos desde una perspectiva cuantitativa.

PALABRAS CLAVE: diversidad de exposición, jóvenes, televisión, cinematografía.
This enquiry looks at young publics' consumption of television programming and films at movie theatres. Using data from 21 interviews, the article argues that the reception patterns of informants keep a strong correlation with the diversity of media platforms and contents to which they have access. Future studies should hopefully confirm our findings from a quantitative perspective.

KEY WORDS: Exposure diversity, young people, television, cinema.

1 Instituto Tecnológico y de Estudios Superiores de Monterrey, Monterrey, México.

Correo electrónico: ts_ame2004@yahoo.com

Dirección postal institucional. Tecnológico de Monterrey, Av. Eugenio Garza Sada No. 2501 Sur, Col. Tecnológico, 64849 Monterrey, N.L., México. 
El presente trabajo de investigación explora y trata de evaluar la diversidad de exposición vertical de los jóvenes del área metropolitana de Monterrey, Nuevo León y de los municipios de Benito Juárez, Quintana Roo y Acámbaro, Guanajuato, a la televisión y al cine, así como la manera en que dicha exposición refleja las condiciones estructurales de la oferta a la cual tienen acceso.

La diversidad de exposición es entendida como la forma en que los individuos reciben los contenidos emitidos por los medios masivos y el uso personal, social y político que ellos hacen de dichos contenidos. Ésta a su vez, dice Napoli (1999), es dividida en diversidad de exposición horizontal y vertical. La primera se refiere a la forma en que la "audiencia de los medios masivos se distribuye a sí misma a través de las opciones de contenido disponibles en un punto del tiempo en particular" (p. 26), y la diversidad de exposición vertical a "medidas que se enfocan en los patrones de exposición dentro de miembros de la audiencia individual" (p. 27).

Las aproximaciones al estudio de la diversidad de exposición en México, y en todo el mundo, han sido escasas. En México han sido evidenciadas por Lozano (2005), Chong, García y Aguilar (2009), y Carabaza et al. (2009) quienes en distinto momento, y lugar, han expuesto información empírica referente a patrones de consumo de contenidos extranjeros. Lozano (2005) realizó un recuento de las investigaciones que hasta ese entonces se habían enfocado en el análisis de consumo y apropiación de contenidos extranjeros en México. Dicho autor constató que a pesar de que había un dominio en las preferencias de los televidentes por programas nacionales, el estrato de los jóvenes, de " $24 \%$ $\ldots$ de clase baja de Irapuato hasta ... 83\% de clase alta en la ciudad de México" (p. 173), mostraban exponerse más a contenidos estadounidenses que a aquellos de su país u otros orígenes. Chong et al. (2009) mostraron que los encuestados jóvenes, y los que tenían mayor escolaridad, veían más programación estadounidense en Torreón, Coahuila, y Carabaza et al. (2009) encontraron que los habitantes de Saltillo, Coahuila, se exponían principalmente a géneros cuyo contenido era de carácter nacional.

Todo pareciera indicar que los últimos hallazgos en México, respecto de dicha exposición, van de la mano de la creciente expansión y acce- 
sibilidad a la televisión digital y por cable (Comstock \& Scharrer, 1999; Jingyan, 2007; Rubin, 2002; Van de Wurff, 2004; Webster 1986), de la cantidad de tiempo consumido de frente a la televisión (Perse, Ferguson \& McLeod, 1994), y/o de un significado cultural y social (Biltereyst, 1992; La Pastina \& Straubhaar, 2005; Lull, 1980; Morley, 1992, 1986; Renckstorf \& Wester, 2004; Straubhaar, 2003) tal como lo evidencian otros resultados alrededor del mundo.

Sin embargo, el escaso trabajo empírico nacional obliga a reflejar la forma en que audiencias jóvenes bajo distintas circunstancias, y en distintas posiciones, se exponen o no a determinados programas de acuerdo a su género y origen. Cuando hablamos de miembros de audiencias, nunca debemos olvidar mencionar a los jóvenes porque son esa parte de la población íntimamente ligada a la transición a un mundo globalizado en el cual las manifestaciones culturales y los intentos de dominación y manipulación, a través de la televisión y el cine, se convierten en una constante por la multiplicidad de industrias culturales con su limitada oferta en términos de formato/tipo, origen de su programación (Lozano, 2006, p.145), y origen de las películas exhibidas en las salas de cine (Martínez, García \& Menchaca, 2007, p. 50). Además, por las pruebas empíricas existentes acerca de los patrones juveniles de la recepción de los medios y su influencia en patrones a futuro (Drotner, 2000, p. 149).

El presente trabajo pretende contribuir en el desarrollo y entendimiento del concepto de diversidad vertical dentro del consumo de las audiencias televisivas y cinematográficas en México. Proporcionar información útil que permita diagnósticos del grado de diversidad experimentado en el consumo televisivo de los jóvenes. Y por último, proveer elementos que faciliten estrategias para una mayor educación de audiencias acerca de medios masivos de comunicación.

De entre los enfoques teóricos que aportan evidencia empírica sobre los patrones de exposición a la televisión, la presente investigación se apoya en la teoría de la acción social y estudios culturales. La teoría de la acción social ha probado que la selección y elección de un programa, dentro del contexto social de la vida familiar, es raramente un asunto individual pero el resultado de la interacción grupal: "entre más gente haya para negociar la elección de un programa, más 'empobrecida' se convierte la elección del programa de la familia" (Renckstorf \& Wester, 
2004, p. 69). Konig (s.f.), siguiendo la misma línea teórica, encontró en Holanda que "las creencias religiosas no parecen tener influencia en las preferencias de las personas por el género de los programas televisivos, y demuestra que no hay una correlación entre el comportamiento dominante y la selección de programas de televisión" (p.2). Los estudios culturales, por otro lado, han evidenciado relaciones de poder y género dentro de la familia, y afinidad lingüística e histórica como fuertes influencias al momento de elegir un programa. Respecto de la primera, Morley (1986) encontró que el "poder masculino es evidente en un número de familias como la última determinante en ocasiones de conflicto generadas por las elecciones de exposición" (p. 141), y Lull (1980, p. 319) halló diferenciaciones entre individuos orientados conceptual y socialmente en el uso de la televisión como recurso para alcanzar sus objetivos interpersonales en casa. En cuanto a la afinidad lingüística e histórica, Biltereyst (1992, p. 517) sostiene que la proximidad lingüística y cultural es un generador extremadamente importante en el consumo de ficción en países europeos pequeños. La Pastina y Straubhaar (2005, p. 285) expusieron las preferencias de la gente rural en Brasil por telenovelas mexicanas y de la gente del sur de Italia por una telenovela acerca de la emigración a Brasil, y Jingyan (2007) mostró que en Guangzhou, China "los programas del mismo idioma muestran tener más audiencias duplicadas aún si ellos no son del mismo canal" (p. 103).

De los enfoques teóricos antes mencionados, se han tomado cuatro conceptos clave como medio de apoyo, comprobación y evaluación de los mismos en circunstancias y realidades distintas con jóvenes del área metropolitana de Monterrey, y de los municipios de Acámbaro y Benito Juárez: repertorio de canal, lealtad de la audiencia, poder diferencial y proximidad cultural. Distintas son las definiciones que se han utilizado para realizar trabajo empírico respecto del repertorio de canal. Jingyan (2007) elaboró un recuento de dichas definiciones y propuso una con características multifuncionales para el estudio de las audiencias. La evolución junto con la multiplicidad de variaciones del concepto van de la mano de la incorporación de nuevas tecnologías en el medio ambiente y el uso doméstico de las mismas. De Heeter y Greenberg a Neuendorf, Atkin y Jeffres (citados en Jingyan, 2007, pp. 122-123), el concepto ha sido tipificado de distintas maneras: repertorio de canal, frecuencia ponderada de repertorio, reperto- 
rio primario, secundario y terciario. Sin embargo, para el análisis del presente trabajo se entenderá dicho concepto como el "subconjunto de canales disponibles que cada individuo ve intensivamente" (p. 86). Es decir, puesto que el espectador tiene un repertorio más extenso, es más propenso a exponerse a una cantidad de programas más diversos.

Aunque el concepto de lealtad de la audiencia ha sido poco discutido, diversos trabajos indican que dos son las categorías clave para el análisis de las manifestaciones de comportamiento: la polarización de la audiencia y la duplicación de la audiencia. Lealtad de la audiencia se entiende como "la intensidad con la cual los miembros de la audiencia usan los ítems de contenido" (Yim citado en Jingyan, 2007, p. 61). Es decir, la tendencia de los miembros de la audiencia a consumir o evitar cierta clase de contenido, lo cual se llama "polarización de la audiencia” (p. 62), y el grado en el que la audiencia de un programa también ve otro programa, que se llama "duplicación de la audiencia" (Cumstock \& Scharrer, 1999, p. 101).

El poder diferencial fue típicamente utilizado por Morley (1992) para ejemplificar la selección de programas dentro del contexto familiar; él decía que:

Considerar las maneras en que la exposición es realizada dentro de las relaciones sociales de la familia es considerar las maneras en que la exposición es realizada dentro del contexto de las relaciones de poder, y en términos de poder diferencial alcanzado a miembros de la familia en distintos roles envolviendo género y edad (p. 134).

Es decir, el posible rol dominante de algunos miembros de la familia y el grado en que dichos miembros influyen para la selección de canales. La evidencia empírica ha demostrado que los padres de familia son los principales promotores de la exposición a contenidos televisivos dentro del espacio familiar.

La Pastina y Straubhaar (2005), por otro lado, han desarrollado el concepto de proximidad cultural. Dichos autores han realizado discusiones respecto de las categorías de lugar e identidad con base en hallazgos de investigaciones recientes en Brasil e Italia. Proximidad cultural, dice Straubhaar (2003), se refiere a la forma en que: 
Capital cultural, identidad, e idioma tienden a favorecer un deseo de la audiencia por la proximidad cultural, el cual conduce a las audiencias a preferir producciones locales y nacionales de aquellas que están globalizadas y/o americanizadas. Sin embargo, la proximidad cultural está limitada por estratificación de clase social (p. 76).

En otras palabras, se trata del grado en que determinadas audiencias con capital cultural seleccionan determinado programa o película con base en patrones de identificación con el contenido. Investigaciones recientes han demostrado que es necesario considerar la proximidad cultural no solamente en su sentido original, "sino también en términos de valores locales compartidos y alianzas históricas entre la cultural original del texto y la cultura local" (La Pastina \& Straubhaar, 2005, p. 286). Por ejemplo, mujeres de Brasil prefiriendo novelas mexicanas sobre las locales, o ciudadanos italianos viendo películas de migrantes brasileños.

Con base en lo anterior, se elaboraron las siguientes preguntas que se trataran de responder con la información recabada:

1. ¿Cuáles y qué tan diversos son los patrones de exposición de jóvenes neoleoneses, guanajuatenses y quintanarroenses a la televisión $\mathrm{y}$ al cine?

2. ¿Existen factores que impiden o desmotivan un consumo más diverso en cuanto a formatos y orígenes?

3. ¿Existen diferencias de acuerdo a variables como el sexo y ubicación geográfica de los jóvenes en los grados de diversidad de consumo televisivo y de cine?

4. ¿Es la limitada oferta de programación en cuanto a origen y formato una determinante para que los jóvenes entrevistados seleccionen lo que quieren ver?

\section{MÉTODO}

La presente investigación fue ralizada a través de la técnica de entrevista focalizada cualitativa aplicada a una muestra de 21 individuos de entre 15 y 26 años de edad diferenciados por la variable de género y ubicación geográfica tanto de escuelas públicas y privadas de nivel medio superior 
y superior del área metropolitana de Monterrey, Nuevo León, y de los municipios de Benito Juárez, Quintana Roo, y Acámbaro, Guanajuato, durante los meses de julio de 2009 a enero de 2010.

Las preguntas de investigación fueron respondidas con la información recolectada en dichas entrevistas. Hemos de reconocer que el número de entrevistados, hombres y mujeres, fue muy limitado por razones no solamente económicas sino también geográficas. Sin embargo, nuestra intención era analizar cómo dicha exposición representaba la oferta en cuanto origen y género de los programas, y cómo audiencias de distinto género y localización geográfica respondían o actuaban con relación a dicho contenido durante la semana.

No se pretendió establecer muestras representativas de jóvenes de cada localidad, sino contar con un grupo de informantes geográfica y culturalmente diverso dentro de México, para facilitar la detección de patrones recurrentes y comunes en todos ellos y abarcar en lo posible la diversidad de consumo audiovisual presente en los jóvenes mexicanos. Los hallazgos y las comparaciones entre los tres grupos de informantes no deben tomarse más que como evidencia de la gama de consumo diverso que puede existir en un solo grupo de edad: el de los jóvenes mexicanos de ese rango de nivel socioeconómico.

Serealizó una prueba piloto con la cual se generaron preguntas más precisas con relación a las variables de tipo y origen de los programas y películas a los que se exponen los individuos. Guía y dinámica fueron realizadas con base en la literatura encontrada respecto del tema. La guía contenía preguntas abiertas estructuradas y relacionadas a la técnica mencionada. La dinámica hacía participe a los individuos en la supuesta realización de una programación televisiva y disposición de películas. Al final, solamente se realizaron el número de entrevistas mencionado con base en dicha técnica.

La sistematización de la información se realizó a través del programa computacional Nvivo. En dicho programa se recopiló toda la información de las respuestas de los individuos referente al objetivo y las preguntas de investigación. La información, más tarde, fue utilizada en la descripción de los resultados, la interpretación y las conclusiones.

La variable ubicación geográfica fue estratificada con el ingreso semanal de las familias de cada entrevistado, de manera tal que al final 
se realizó una diferenciación entre aquellos individuos procedentes de escuelas tanto públicas como privadas pero con un ingreso familiar similar. Es decir, diferenciando a aquellos individuos que por igualdad de circunstancias estuvieran estudiando en una institución privada o pública, pero que tuvieran un ingreso semanal diferenciado por razón geográfica: rural o urbana.

\section{RESULTADOS}

1. ¿Cuáles y qué tan diversos son los patrones de exposición de jóvenes neoleoneses, guanajuatenses y quintanarroenses a la televisión y al cine?

Debemos de comenzar por mostrar que los patrones de consumo de los jóvenes en los tres lugares mencionados estuvieron diferenciados por lo que decidimos llamar periodo pre-adolescente (de 8 a 15 años; dependiendo del género), y jóvenes (de 18 a 26 años). Es decir, los miembros de los tres lugares mostraron patrones de exposición cuando eran pre-adolescentes, los cuales fueron modificados al alcanzar la mayoría de edad.

En la Tabla 1 se muestra la clasificación de las entrevistas, así como el código con el que serán referenciadas las mismas.

TABLA 1

CLASIFICACIÓN DE LAS ENTREVISTAS

\begin{tabular}{ccccl} 
No. & Lugar & Género & Razón geográfica & \multicolumn{1}{c}{ Código } \\
\hline 1 & Monterrey & Masculino & Urbana & 01.MascUrbMty \\
2 & Monterrey & Femenino & Rural & 02.FemUrbMty \\
3 & Monterrey & Masculino & Urbano & 03.MascUrbMty \\
4 & Monterrey & Masculino & Rural & 04.MascUrbMty \\
5 & Monterrey & Femenino & Urbano & 05.FemUrbMty \\
6 & Monterrey & Femenino & Urbano & 06.FemUrbMty \\
7 & Monterrey & Femenino & Rural & 07.FemRurMty \\
\hline 8 & Acámbaro & Femenino & Rural & 08.FemRurGto \\
9 & Acámbaro & Masculino & Rural & 09.MascRurGto \\
10 & Acámbaro & Femenino & Rural & 10.FemRurGto \\
11 & Acámbaro & Masculino & Urbano & 11.MascUrbGto
\end{tabular}




\begin{tabular}{ccccl} 
No. & Lugar & Género & Razón geográfica & \multicolumn{1}{c}{ Código } \\
\hline 12 & Acámbaro & Masculino & Urbano & 12.MascUrbGto \\
13 & Acámbaro & Femenino & Rural & 13.FemRurGto \\
14 & Acámbaro & Masculino & Rural & 14.MascRurGto \\
\hline 15 & Benito Juárez & Masculino & Rural & 15.MascRurQroo \\
16 & Benito Juárez & Masculino & Rural & 16.MascRurQroo \\
17 & Benito Juárez & Masculino & Rural & 17.MascRurQroo \\
18 & Benito Juárez & Masculino & Rural & 18.MascRurQroo \\
19 & Benito Juárez & Femenino & Urbano & 19.FemUrbQroo \\
20 & Benito Juárez & Femenino & Urbano & 20.FemUrbQroo \\
21 & Benito Juárez & Femenino & Urbano & 21.FemUrbQroo \\
\hline
\end{tabular}

Por patrones se entiende la exposición a caricaturas tanto estadounidenses como japonesas, a deportes series de comedia estadounidenses; noticieros no solamente locales sino también nacionales e internacionales, películas de drama, suspenso, acción, comedia y terror. Sin embargo, todas ellas tienen una diferenciación tanto antes como después de dicho periodo.

Las caricaturas, por ejemplo, fueron mencionadas por la mayoría de los entrevistados como un género determinante en el periodo de preadolescencia de la mayoría de los jóvenes tanto de Monterrey como de Acámbaro y Benito Juárez. Sin embargo, se aprecia una diferencia en la forma de escoger dichas caricaturas, por ejemplo, los jóvenes entrevistados de origen urbano mencionaron que la caricatura de Los Simpson era obligatoria en su consumo diario de televisión:

Mi hermano y yo no podemos dormir si no vemos un capítulo de Los Simpson. Como que ya se hizo tradición" (03.MascUrbMty).

Los Simpson están en todo, o sea, cubren todos los horarios (11.MascUrbGto).

me gustan mucho los estrenos de...o los especiales de los programas culturales y, por ejemplo, National Geographi- NATGEO; Los Simpson, no hay día que no me los pierda, ya llevo viéndolos desde muy chavo (12.MascUrbGto). 
Los jóvenes que tenían orígenes más rurales se enfocaron en caricaturas un tanto más místicas, o de ficción, de origen japonés. Ranma y medio y Dragón Ball $Z$ son algunos ejemplo de ello. Así se refería uno de los entrevistados al respecto:

Veía mucho Ranma y medio, igual ese creo es anime japonés, o Manga, no creo ese también. Me gustaba mucho verlos. También me gustaba mucho una serie que se llama Nicam, de una caza fantasmas (18.MascRurQroo).

Acerca de las series de televisión, todos ellos encontraron una cierta afinidad con las de origen estadounidense, principalmente aquellos individuos provenientes de zonas urbanas. Mientras que los de origen más precario en ocasiones mostraron poca afinidad o nula por dicha programación, y algunos de ellos se enfocaron en simpatizar con canales de música de banda, sonorense o pop.

Al hablar de películas, muchos de los individuos entrevistados de origen rural mostraron una cierta exclusión o desconocimiento de aquellas películas de actualidad exhibidas en las salas de cine, y se enfocaron más en las películas mexicanas televisadas. Es importante mencionar que aquellos individuos que tuvieron dicha afinidad son los que más frecuentemente ven televisión con sus familias o al menos siguen los patrones de exposición de las mismas. A continuación se muestran algunos de sus comentarios:

A mis papás, pues ahora sí que de todo. A mis papás les gustan las películas... de todas, hasta eso comparten, bueno no sé si comparten o yo comparto el gusto con ellos que no nos gustan como películas fantasiosas... no, o sea, muy irreal, muy ficticia... no sé, por ejemplo, pudieran ser las películas mexicanas (09.MascRurGto).

De allá de trabajar, y ya cuando terminamos de comer, y ya se van los que estén. Como es cuando estoy con mi mamá, y así buscan películas... cuando es aquí abajo, si porque está mi mamá, mis hermanos, mi abuelita... como ella es tan así... películas... de... como ya están... a mi mamá "Gelo", le gustan puras mexicanas, pura mexicana así de Pedro Infante (08.FemRurGto). 
Los individuos con mas independencia familiar y viviendo en zonas urbanas mostraron tener más afinidad por las películas estadounidenses aunque algunos de ellos fueron muy críticos al pensar que la oferta de películas en las salas de cine se debía a una cierta hegemonía de Estados Unidos. Esto fue demostrado con base en ejemplificaciones no solamente en la televisión, sino también en las salas de cine de su localidad o preferencia. Así es como se refiere uno de los informantes respecto de lo dicho:

Es que el problema aquí en México, es que la mayoría son películas americanas, o sea, tristemente vas a rentar películas y $90 \%$ son americanas, y $5 \%$ mexicanas, y el otro 5\% europeas. Esas son bien raras encontrar. A mí me gustan mucho las películas europeas, por ejemplo, el drama español, que es muy bueno. Habla mucho de la multiculturalidad, o la de Amelie, que es francesa, está muy buena. Ese estilo me gusta mucho (01.MascUrbMty).

Puesto que nuestro objetivo no fue analizar clase social sino localización geográfica y género, buscamos detectar las posibles diferencias en cuanto a las formas de vinculación de cada individuo con la producción audiovisual ofertada no solamente en la televisión sino también en las salas de cine disponibles a los individuos entrevistados.

Una de las primeras complicaciones a las que se llegó fue a la definición de los límites bajo los cuales los individuos toman sus antecedentes culturales para exponerse a dichos programas y películas. Es decir, si los individuos eran motivados o influenciados por hechos pasados durante su pre-adolescencia o eran afectados más bien por un tipo de socialización posterior en su vida adolescente a través de sus padres o amigos. Dicha interrogante en parte fue respondida con las categorías expuestas por cada individuo. Sin embargo, pensamos que es importante cuantificar dichos patrones y obtener análisis del grado de influencia que hay respecto de la exposición a programas en la etapa de pre-adolescencia y después. De la misma forma, pensamos que es menester medir dichas influencias y exposiciones en los distintos lugares, o sitios geográficos, para confrontar los resultados de las mediciones con las teorías planteadas en el campo de estudio.

Podemos decir que hay una diferenciación entre aquellos individuos entrevistados en situaciones de precariedad, y aquellos viviendo en con- 
diciones urbanas. Es decir, la mayoría de los primeros se identificaban por su preferencia a programas y películas de terror, místicas o de ficción, no solamente de origen estadounidense, sino también mexicanas, europeas y asiáticas acaecidas en la programación de la televisión local. Mientras que aquellos que eran de origen urbano mostraron preferencia hacia programas y películas en su mayoría de origen estadounidense, sin importar su acceso a televisión de paga o libre.

2. ¿Existen factores que impiden o desmotivan un consumo más diverso en cuanto a formato y orígenes?

Puesto que los jóvenes entrevistados son de distinta localidad geográfica, y con base en la diferenciación vislumbrada con anterioridad con relación a la edad o periodo de desarrollo personal, se han identificado ciertos factores que impiden o desmotivan la diversidad en el consumo de programas en cuanto al formato y origen de los mismos según cada individuo. Los individuos no solamente de origen rural o poco desarrollado sino también aquellos de lugares urbanos mencionaron que hay una influencia de ciertos miembros de su familia al momento de exponerse a la televisión o el cine. A veces lo anterior se daba por simpatía con el otro; otras más como imposición de un miembro de la familia al solamente existir una televisión para todos, y en determinadas situaciones por la convivencia familiar. Lull (citado por Morley, 1986) y Renckstorf y Wester (2004) ya daban cuenta de ello. El primero describió la influencia del padre de familia al momento de seleccionar programas televisivos en determinadas situaciones de crisis familiar, mientras que Renckstorf y Wester demostraron la influencia del contexto social en la elección de lo que se quiere ver. A continuación se muestran fragmentos de lo expresado por algunos de los informantes:

Llego y a ver lo que hay. A veces ni eso porque llego a comer y ya están sentados todos viendo un canal y no le puedo cambiar... cuándo están todos... Mi papá... más que nada es el que llega primero a sentarse a la mesa ( 03 . MascUrbMty).

Y los domingos si casi por lo regular no; como casi no estamos, o viene mucha visita, y como que no da tiempo de ver televisión... luego veía los 
Teletubbies, pero porque mis hermanos la veían... ella (mi hermana) veía las cosas, y pues yo llegaba y ya no me permitía yo cambiarle. Como llegaba más tarde que ellas, como así, ya ellas se habían apoderado de la televisión, y ya me tenía que quedar viendo lo que ellas veían...Cuando ya tuve mi televisión independiente a la de los demás; cuando yo ya tuve mi televisión y ellos tenían otra, como que ya yo me apartaba y ya, pero eso fue hasta hace poquito (08.FemRurGto).

Cuando voy al cine normalmente me dejo llevar por mi novio, ahí sí. A menos de que tenga muchas ganas de ver algo porque si no, o sea, si no la voy a ver al cine, la rento, o no tengo ningún problema en no verla, y usualmente cuando me toca ver ciencia ficción o acción, es más impactante para mí... normalmente en el cine es él... Es que como es muy rara la película que no me guste, realmente no tengo problema, y a él... él si tienen problemas con algunas películas, o sea, yo si puedo ver las de drama, melosas... también le gustan a él...como comedia romántica, digamos, pero yo soy de que puedo ver todo y nada me cansa (06.FemUrbMty).

Un factor también importante en el contexto mexicano, o al menos en los jóvenes de las ciudades entrevistadas, es el factor del tiempo de recreación. Es decir, aquel destinado a descansar, distraerse o entretenerse, y en cierta forma olvidarse de la rutina diaria del trabajo o la escuela. Muchos de los individuos, aun aquellos proveniente de familias en condiciones más confortables, argumentaron verse limitados por el tiempo destinado a dicho rol durante todos los días de la semana ya que algunos de ellos no solamente trabajaban o estudiaban, sino también eran parte de asociaciones sociales, civiles o al menos se encontraban ocupados con tareas domésticas. Por ejemplo:

Por lo general es en las horas libres, a veces tengo una hora libre o dos horas libres y no puedo dormir y es cuando me pongo... En la noche no mucho, por lo general si salgo a las 9:00 ya sólo hago mi tarea, tal vez vaya al gimnasio y ya me acuesto. Cuando más veo televisión, es en los días martes y jueves que salgo a las 7:30 p.m... Creo que ya salió, pero no tengo mucho tiempo para ir al cine (04.MascUrbMty). 
Pues tengo limitado el tiempo por la escuela y el trabajo. Y aparte de éste tengo otro trabajo... Televisa acá no hay... es que estás limitado ... o que prefieres escuchar música o, como dicen, ver películas o mejor irte a trabajar y ganarte unos centavos. No sé... como se dice, por tiempo. Si me da tiempo la tele, pues veo la tele, sino la radio, pues la radio (17.MascRurQroo).

No. Antes sí; ahorita no ya veo muy poca televisión. De hecho cuando paso, tengo una hora o una hora y media, prendo la televisión y sí veo que me llama algo la atención la veo, mientras no. Si veo que no, la apago... En la calle. En el trabajo, no sé. Luego tengo cosas que hacer y me salgo. Pendientes que me deja mi mamá, pendientes del trabajo y cosas así... Es una limitante en el sentido de que no tengo mucho tiempo para estar cerca o pegado a la televisión, pero sí de mí dependiera ver los programas que me gustan, la limitante sería el tiempo (18.MascRurQroo).

En particular, algunos individuos del municipio de Acámbaro, Guanajuato, atribuyeron su influencia a la exposición de programas estadounidenses a la necesidad de obtener narrativas para compartir con familiares que viven en algunas ciudades de Estados Unidos. Canales como Telemundo, que tiene programación de manufactura hispana y lengua española, son típicamente a los que se exponen los jóvenes de dicho municipio. Ellos expresan que no solamente se exponen a la programación de dichos canales para sostener temas de conversación telefónica con familiares o amigos, sino también por la experiencia personal de visitas previas, o la convivencia con algún individuo o vecino que haya vivido en Estados Unidos.

Entonces, podemos identificar el contexto familiar, el tiempo de recreación y el tráfico o migración constante de individuos hacia ciudades de Estados Unidos como factores que impiden o desmotivan un consumo más diverso en cuanto a género y origen en jóvenes de los tres lugares mencionados.

3. ¿Existen diferencias de acuerdo a variables como el sexo y ubicación geográfica de los jóvenes en los grados de diversidad de su consumo televisivo y de cine?

Es interesante mencionar que las mujeres se diferenciaron con base en 
los mecanismos expuestos anteriormente. Es decir, mientras más nos acercábamos hacia lo rural, donde se presentaban formas de interacción más tradicional, las mujeres reaccionaban mostrando más atracción a contenidos místicos en programas y películas a los que se exponían. Dichos contenidos correspondían a géneros como ficción, terror, o suspenso. Una de las entrevistadas esto fue lo que comentó:

¿Qué más veo? La novela... ajá; veo las novelas... Ahorita veo la de Camaleones... Este, ¿qué más veo? Veo la Rosa de Guadalupe, también... la de, este, Atrévete a soñar... Programas, la de, este, Muévete... A ver, ¿qué más podría ser?... Ajá. A las 3:00, también a veces veo La familia peluche, a las 4:00 las novelas, a las 5:00 a las 6:00 (13.FemRurGto).

Las de áreas urbanas mostraban una cierta afinidad por series y películas estadounidenses. Friends, Lost y The Da Vinci Code son algunos de los programas y películas que mencionaron. Además, algunas de ellas también expresaron ver adaptaciones mexicanas de otros países, por ejemplo, Mujeres asesinas; una de las entrevistas, esto fue lo que dijo:

Esa es la cosa que cuando tengo tiempo libre, prendo la tele y estoy en el Warner Bros o en el Sony. Sé, por ejemplo, que Two and a half y Friends son a las 12:00 pm y a la 1:00 pm porque a veces coinciden con mi ida al gimnasio. Como... viendo tele, hago que coincida para que se me pase más rápido. Y en la mañana que me levanto, me pongo en el riel y también pongo el Sony, porque son programas que me... o, por ejemplo, en el gym me recomendaron $D r$. House, y ése está en AXN. Entonces, primero renté a Dr. House, y ya cuando me di cuenta que la pasaban en Universal, la empecé a seguir en Universal, pero no. Normalmente yo no busco ni AXN ni Universal que es normalmente dónde sacan Lost; dónde sacan ésas a las que me refiero (06.FemUrbMty).

El caso masculino mostró preferencias de consumo televisivo y cinematográfico similares a los de las mujeres tanto de contexto rural como urbano. Sin embargo, se evidenciaron excepciones en programas documentales, musicales, y demás, los cuales seleccionaban para entretenerse o mantenerse informados según argumentaciones de algunos de los entrevistados; por ejemplo: 
Sí, me gustan (los documentales)... Pues hay los de animales, de guerra, y todo ese tipo... En NATGEO y en Discovery... Son como cultura general para mí, prefiero verlos a ver un programa de chismes. Son temas que algún día van a surgir en la plática, y entonces, se me graba más viéndolo que estudiándolo (11.MascUrbGto).

Individuos, tanto hombres como mujeres, de lugares urbanos mostraron una mayor participación al momento de decidir respecto de lo que querían ver o exponerse. Por ejemplo, algunos mencionaron que asistían al cine a ver películas de acción de origen estadounidense o las rentaban sin importar su nacionalidad. Y un gran grueso de la población femenina entrevistada, tanto del ámbito rural como urbano, coincidió en rentar películas de distinto género y origen mientras éstas abordaran una buena temática y hubieran sido premiadas en concursos internacionales. En conjunto, mujeres y hombres tanto de rural como de urbano coincidían en ver caricatura o ficción de origen internacional y noticias locales.

Consecuentemente, hombres y mujeres de los distintos orígenes mostraron una ligera diferenciación en la forma de consumir televisión y cine con excepción de las mujeres de origen rural, las cuales se enfocaban más en las telenovelas y películas mexicanas transmitidas a través de la televisión.

4. ¿Es la limitada oferta de programación en cuanto a origen y formato una determinante para que los jóvenes entrevistados seleccionen lo que quieren ver?

En la mayoría de los entrevistados se vislumbran dos momentos a la hora de seleccionar contenidos de la televisión. Están aquellos momentos en los que el individuo selecciona con base en sus expectativas de entretenimiento, información o por sugerencia de algún otro individuo conocido, y el otro es cuando éstos piensan gastar cierto tiempo frente a la televisión sin importarles en cierta medida lo que haya o encuentren.

Diversos estudios han demostrado que algunas causales para que individuos seleccionen lo que quieren ver es el contexto que los rodea. En otras palabras, si el individuo se encuentra socialmente acompañado por sus familiares o un grupo de amigos, éstos van a influir en la selección de la exposición. Morley (1986) argumenta que "los individuos usualmente 
ven programas que son elegidos por alguien más en la familia" (p. 24). Guadarrama (1996) afirma que "el contenido televisivo [en sí mismo] convoca e interpela diferencialmente a ... miembros de la familia de acuerdo con la historia de cada uno, género, generación, rutina y ubicación jerárquica que ocupa dentro de la familia" (p. 52). Rencktort y Wester (2004) dicen que "entre más gente haya para negociar la elección de un programa, más 'empobrecida' se convierte la elección del programa de la familia" (p. 69). De esta forma, podríamos decir que ambos momentos, tanto cuando se comportan los individuos de manera activa o pasiva, se van a ver interactuando en un ámbito de acción para la selección de la exposición de manera tal que las medidas de influencia precisas de cada cual solamente serán evidenciadas con estudios cuantitativos en el orden de los factores que componen dicha relación.

Por otro lado, si tomamos en cuenta la diversidad de contenido en cuanto a género y origen disponible en la programación de la televisión y las películas exhibidas en las salas de cine en México, encontramos que hay coincidencias respecto de la oferta de la programación y el consumo de los jóvenes entrevistados en el presente estudio. Por ejemplo, Huerta (2000) y Martínez y Lozano (2005) encontraron que los programas con mayor presencia en la televisión mexicana son aquellos clasificados dentro de los géneros de ficción, informativos e infantiles, mientras que los jóvenes antes mencionados dijeron exponerse a caricaturas, deportes, series de comedia y noticieros. Es decir, se evidencia una cierta relación entre el contenido disponible y la exposición de los jóvenes entrevistados.

Sin embargo, cuando se les cuestionaba si les gustaría que hubiera más programas disponibles en la televisión, los jóvenes de procedencia urbana contestaron de manera positiva aunque sostuvieron que ellos tenían la opción de utilizar otras fuentes de suministro de información y entretenimiento como el Internet para encontrar lo que fuera de su agrado. Los jóvenes de origen rural, por su parte, mostraron tener poco interés respecto del tema de la disponibilidad de más programas, argumentando tener el contenido suficiente en la oferta actual para seleccionar lo de su preferencia.

En lo que concierne al origen del contenido de la programación, Martínez y Lozano (2005) evidenciaron que la mayoría de dicho contenido era de origen nacional, $55 \%$ se refería a contenido realizado en 
México, mientras que más de $75 \%$ del resto era proveniente de Estados Unidos, y lo demás de Japón, Francia, España, Inglaterra, Colombia, Brasil y Venezuela. En este sentido, la mayoría de los informantes, sin importar sexo o ubicación geográfica, coincidieron que respecto del género de ficción encontraban un cierto dominio estadounidense en la oferta disponible. Sin embargo, dijeron que también encuentran a su disposición programas, como caricaturas, telenovelas y noticias, que provienen de otros países. Los de zonas rurales, particularmente, señalaron preferir programas mexicanos y locales.

El caso del cine es similar. Dichos autores sostienen que 8 de cada 10 películas exhibidas en las salas de cine son de origen estadounidense (Martínez \& Lozano, 2005, p.61), mientras que los jóvenes entrevistados de origen urbano declararon asistir más a exhibiciones de películas de dicho país. Sin embargo, los de origen rural dijeron preferir mexicanas transmitidas en la televisión.

En general, se puede decir que hay una estrecha relación entre la diversidad de contenido en cuanto al género y origen de los programas transmitidos en la televisión y las películas exhibidas en las salas de cine, y la exposición de los jóvenes entrevistados. Sin embargo, se muestran excepciones en lo que concierne a las películas mexicanas y la preferencia de individuos de origen rural. Chong et al. (2009, p. 45), en un estudio acerca del consumo televisivo en Torreón, evidenció que individuos jóvenes, y con mayor escolaridad, veían más programación estadounidense. Esto nos sugiere que aunque las circunstancias y elementos de análisis en ambos estudios son distintos, se podría reforzar la idea de que los individuos de origen rural y urbano podrían estar diferenciados por el grado de cosmopolitanismo cultural en ellos mismos. Es decir, pareciera que los primeros se exponen más a televisión nacional, que los de origen urbano, porque tienen un menor grado de dicho cosmopolitanismo en sí mismos.

\section{CONCLUSIONES}

Al comenzar la presente investigación se planteó como objetivo principal identificar que tan diversos y plurales eran los patrones de consumo audiovisual de jóvenes del área metropolitana de Monterrey, Nuevo 
León y de los municipios de Benito Juárez, Quintana Roo, y Acámbaro, Guanajuato, en cuanto a procedencia geográfica y géneros de los programas y películas vistos en los sistemas de televisión abierta, de paga, y en las salas cinematográficas, y en qué medida dichos patrones reflejaban las condiciones estructurales de la oferta a la que tenían acceso. Con base en ello, en la literatura revisada, los conceptos de repertorio de canal, lealtad de la audiencia, poder diferencial y proximidad cultural, y los hallazgos encontrados durante el análisis de los datos, a continuación se presentan algunas conclusiones.

El repertorio de canal es entendido como el "subconjunto de canales disponibles que cada individuo ve intensivamente" (Jingyan, 2007, p. 86). Mientras más extenso sea el repertorio, más propenso es el individuo a exponerse a una cantidad de programas más diversos. Podemos decir que individuos tanto hombres como mujeres de origen urbano y hombres de origen rural tienen un repertorio de canal más extenso porque se exponen a canales tanto nacionales como extranjeros disponibles en los sistema de televisión libre y de paga. Sin embargo, poco se puede argumentar respecto de la diversidad en cuanto a género y origen desde que el grueso de los programas a los que se exponen son de géneros y origenes limitados.

La lealtad de la audiencia ha sido estudiada bajo dos categorías para el análisis de las manifestaciones de comportamiento acaecidas en la audiencia: polarización y duplicación. La una se refiere a la tendencia de los individuos a consumir o evitar cierta clase de contenidos, mientras que la duplicación es el grado en que la audiencia de un programa también ve otro programa. Así observamos que los géneros noticias locales y la caricatura de Los Simpson, son preferidos tanto por hombres y mujeres de origen rural y urbano. Jóvenes neoleoneses buscan usualmente ver series de televisión y películas en inglés, mientras que guanajuatenses y quintanarroenses se exponen principalmente a programas en español.

El concepto poder diferencial fue utilizado por Morley (1992) para ejemplificar la selección de programas dentro del contexto familiar. El autor decía que considerar la exposición dentro de dicho contexto era considerar las relaciones de poder de los miembros de la misma y su género y edad. En el presente estudio encontramos que no solamente los padres de familia tienen un rol significativo en la selección de con- 
tenidos, sino también parejas del género masculino y en ocasiones del género femenino con mayoría de edad. En hombres y mujeres de origen urbano se evidenció una cierta simetría tras declaraciones que argumentaban el hecho de actuar de manera activa respecto de la selección de programas televisivos y películas vistas en el cine.

Straubhaar (2003) se refiere a la forma en que "capital cultural, identidad, e idioma tienden a favorecer un deseo de la audiencia por la proximidad cultural, el cual conduce a las audiencias a preferir producciones locales y nacionales de aquellas que están globalizadas y/o americanizadas" (p. 76). Así, hombres y mujeres de origen rural coincidieron en seleccionar programas y películas de origen nacional en la televisión. Jóvenes neoleoneses declararon exponerse a series televisivas y películas en inglés, mientras que jóvenes guanajuatenses ven canales como Telemundo para mantenerse informados y tener temas de conversación con familiares y amigos viviendo en el sur de Estados Unidos. Para los tres casos mencionados hay una cierta proximidad cultural, e incluso para los jóvenes guanajuatenses sus preferencias de exposición podrían estar ligadas a las semejanzas de los contenidos de dichos programas con su realidad familiar o contexto social.

Durante el desarrollo, evaluación y análisis de la información arrojada en la presente investigación queda una seña respecto de la elaboración de un análisis más profundo en el orden de conceptos como repertotio de canal y lealtad de la audiencia. No podemos generalizar, en el orden de los resultados, conclusiones precisas en dichos conceptos. Sin embargo, encontramos más evidencia empírica concerniente al poder diferencial y proximidad cultural.

Aunque hace falta mucho por hacer dentro del campo de la diversidad y pluralidad de los medios masivos en México, lo que queda claro con la presente investigación es que hay relación entre la diversidad de contenido y exposición a la televisión y al cine. Si bien se evidenció que hay individuos que de manera activa seleccionan el contenido audiovisual al que quieren exponerse, nos parece que es menester evaluar las normas referentes a formatos y orígenes de los contenidos de la programación en televisión y cine. Con un marco normativo actualizado es posible garantizar una oferta plural y diversa a disposición de las audiencias, y con ello proveer los mecanismos para una sociedad más 
crítica con relación al contenido y selección de la información transmitida a través de los canales de televisión y películas exhibidas en las salas de cine.

Futuras investigaciones deberán evidenciar de manera cuantitativa el grado en que audiencias, con el perfil de los jóvenes entrevistados, son influenciadas por los patrones de exposición encontrados, así como también la oferta a la que tienen acceso, y cómo dichas audiencias se diferencian con base en el género y contexto geográfico de los individuos.

\section{Bibliografía}

Biltereyst, D. (1992). Language and culture as ultimate barriers? An analysis of the circulation, consumption and popularity of fiction in small European countries. European Journal of Communication, 7 , 517- 540.

Carabaza, J., Aguilar, A., Coss, B., Hernández, A., González, G. \& Hernández, C. (2009). El consumo de programación extranjera de la televisión nacional: una aproximación a la construcción de la identidad de los habitantes de Saltillo, Cohauila. Global Media Journal México, 6 (12), 1-19.

Chong, B., García, H. \& Aguilar, G. (2009). Consumo televisivo en Torreón. Global Media Journal México, 6 (12), 37-48.

Cumstock, G. \& Scharrer, E. (1999). Television. What's on, who's watching, and what it means. San Diego, CA: Academic Press.

Drotner, K. (2000). Difference and diversity: Trends in young Danes' media uses. Media Culture \& Society, 22, 149-166.

Guadarrama, L. A. (1996). Poder en la familia y televisión. Papeles de Población, 12, 51-62.

Huerta, J. E. (2000). Hacia una evaluación de la televisión mexicana: diversidad en la programación abierta durante 1999. Tesis de maestría no publicada. Tecnológico de Monterrey, Monterrey, México.

Jingyan, E. (2007). The new multi-channel environment in China: diversity of exposure in television viewing. Tesis de doctorado no publicada. Northwestern University, Evanston, Illinois, EE.UU.

Konig, R. (s.f.). Religion and watching television. Recuperado el 13 de noviembre de 2009 de http://rkonig.ruhosting.nl/downloads/paperEtmaal2009.pdf 
La Pastina, A. \& Straubhaar, J. (2005). Multiple proximities between television genres and audiences. Gazette: the International Journal for Communication Studies, 67 (3), 271- 288.

Lozano, J. C. (2005). El consumo y la apropiación de contenidos extranjeros en México. En J. C. Lozano (Ed.), La comunicación en México: diagnósticos, balances y retos (pp. 167- 188). Monterrey: Tecnológico de Monterrey/CONEICC.

Lozano, J. C. (2006, julio-diciembre). Diversidad cultural y televisión en México. Comunicación y Sociedad, 5, 137-156.

Lull, J. (1980). Family communication patterns and the social uses of television. Communication Research, 7 (3), 319- 334.

Martínez, F., García, E. \& Menchaca A. (2007, julio-diciembre). Cambios y modificaciones legislativas: repercusiones en la oferta y el contenido audiovisual en México. Comunicación y Sociedad, 8 , 35-63.

Martínez, F. \& Lozano J. C. (2005, enero-junio). Flujos televisivos y cinematográficos en México. Comunicación y Sociedad, 3, 47-65.

Morley, D. (1986). Family television. Cultural power and domestic leisure. Nueva York: Routledge.

Morley, D. (1992). Television, audiences \& cultural studies. Londres: Routledge.

Napoli, P. (1999). Deconstructing the diversity principle. Journal of Communication, 49, 7-34.

Perse, E., Ferguson, D. \& McLeod, D. (1994). Cultivation in the newer media environment. Communication Research, 21 (1), 79-104.

Renckstorf, K. \& Wester F. (2004). The "media use as social action" approach: theory, methodology, and research evidence so far. En K. Renckstorf, D. McQuail, J. E. Rosenbaum \& G. Schaap (Eds.), Action theory and communication research (pp. 51-83). Berlín: Mouton de Gruyter.

Rubin, A. (2002). Gratifications perspective of media effects. En B. Jennings \& D. Zillmann (Eds.), Media effects. advances in theory and research (pp. 525- 548). Mahwah, NJ: Lawrence Erlbaum Associates, Publishers.

Straubhaar, J. (2003). Choosing national TV: Cultural capital language, and cultural proximity in Brazil. En M. G. Elasmar (Ed.), The im- 
pact of international television (pp. 75-105). Mahwah, NJ: Lawrence Erlbaum Associates, Publishers.

Van der Wurff, R. (2004). Supplying and viewing diversity. The role of competition and viewer choice in Dutch broadcasting. European Journal of Communication, 19 (2), 215- 237.

Webster, J. (1986, verano). Audience behavior in the new media environment. Journal of Communication, 77-91. 